\title{
El legado literario de Antonio Gala: estado de la cuestión
}

\section{Clara Cobo Guijarro \\ Universidad de Santiago de Compostela}

\section{Ana Padilla Mangas}

Universidad de Córdoba
Título: El legado literario de Antonio Gala: estado de la cuestión.

Resumen: El presente artículo contiene la revisión de las principales áreas de estudio que se han desarrollado a lo largo de los últimos cincuenta años acerca de la obra literaria de Antonio Gala. Estos trabajos académicos han abordado las diversas facetas del autor como dramaturgo, novelista y poeta, pero también como guionista o articulista en los principales diarios nacionales. Así, en los diferentes apartados se evaluarán los aspectos más relevantes del legado literario del escritor cordobés en consonancia con la bibliografía derivada de su obra, elaborada por la comunidad académica nacional e internacional. Asimismo, completamos dicho estado de la cuestión con los desafíos y parcelas de discusión pendientes de ser abordados en el futuro.
Title: Antonio Gala’s Literary Inheritance: Status of the Issue.

Abstract: The following article performs a review of the main research areas that, over the Antonio Gala's literary work, have been developed for the last fifty years. These academic works have explored the various facets of the author as a playwright, poet, novelist, but also as a scriptwriter and columnist in the main national newspapers. Thus, in the different sections, the most relevant aspects of Antonio Gala's literary legacy will be evaluated in consonance with the bibliography derived from the national and international academic community. Likewise, we add to this state of the art the challenges and pending discussions to be adressed in the future.

Key words: Antonio Gala, Bibliography, Literary Studies, State of the Art, Theater, Poetry, Novel, Mass Media.
Palabras clave: Antonio Gala, Bibliografía, Estudios literarios, Estado de la cuestión, Teatro, Novela, Poesía, Medios de comunicación.

Fecha de recepción: 29/7/2019.

Fecha de aceptación: 14/9/2019.
Date of Receipt: 29/7/2019.

Date of Approval: 14/9/2019. 


\section{Preliminares}

Antonio Gala ha recordado en múltiples ocasiones el día en el que comprendió la utilidad de la literatura. Tenía cinco años cuando fue castigado sin salir de casa un domingo. En aquella jornada escribió su primer cuento: la historia de su gato. Su padre, al leer lo que había escrito en el cuadernillo, le levantó el castigo. Y Gala comprendió, con ese gesto, que la literatura es liberadora.

Tiempo después comenzó a escribir poesía, aunque no fue hasta 1959 cuando el ejercicio poético adquirió otra magnitud en su vida al recibir el accésit del Premio Adonáis por su poemario Enemigo intimo. En 1963 fue galardonado con el Premio Calderón de la Barca por Los verdes campos del Edén, éxito seguido de muchos más en los escenarios, pues algunas de sus obras se mantuvieron más de dos años en cartel. El mismo año celebró la concesión del Premio Las Albinas por su relato "Solsticio de invierno", pero pasaron casi treinta hasta que publicara su primera novela, El manuscrito carmesi (1990), por la que obtuvo el Premio Planeta. Esta pieza narrativa — también las que vinieron después - fue acogida generosamente por el público. Gala se convirtió en uno de los autores más vendidos del país en aquella época. El autor no solo compaginaba estos tres géneros literarios, sino que durante ese tiempo también fue guionista de exitosas series televisivas y columnista en los principales periódicos del país. Los papeles de agua, su última novela, se publicó en el año 2008, pero el cordobés continuó elaborando sus "troneras" para el diario El Mundo auténticos soplos de franqueza, compromiso y sensibilidad- hasta que firmara la última el 21 de diciembre de 2015. La tituló "Vivir la vida"

Gala siempre ha asumido con tal naturalidad el oficio de la escritura que ni el éxito ni la popularidad han tergiversado su propio concepcto

1 De acuerdo con Isabel Martínez Moreno, Gala fue el autor más vendido en la Feria del Libro de Madrid durante el período comprendido entre 1993-1999. Sus obras han sido traducidas al francés, inglés, alemán, italiano, portugués, árabe, ruso, esloveno, húngaro, griego, japonés, etc. Asimismo, su teatro ha sido representado en multitud de países de Europa y América [Isabel Martínez Moreno, "Premios y distinciones", Antonio Gala: eterno y de Cristal, ed. Isabel Martínez Moreno, Sevilla, Junta de Andalucía, 2016, pp. 212-213 (p. 213)]. 
de la creación. Él mismo explica que "el arte - la poyesis, la creación, en definitiva, la poesía - es como un líquido que adquiere la forma del recipiente en que se vierte [...]. No obstante, todo se construirá con la materia de los sueńos, en el noble y no en el empalagoso sentido de la expresión: todo estará hecho de poesía” ${ }^{2}$. Lo ha demostrado a lo largo de su trayectoria literaria con indiscutible probidad. Ciertamente, son poesía su "poesía de poemas», como él la denomina, pero también los diálogos de su teatro, las "Charlas con Troylo" o las desesperadas confesiones de Desideria en los cuadernillos que escribe a solas en un apartamento en Estambul. Gala es un hombre de fidelidades. Quizá sea "fidelidad" — tal y como confesó a François Dubosquet treinta años atrás- el término que mejor le define. Fidelidad a sí mismo, a su momento y a sus raíces:

Estas tres fidelidades son, sin duda ninguna, la clave de un destino extraordinario - en el sentido primero de la palabra "fuera del común"- que hicieron de un joven poeta nacido en la frontera de Andalucía, criado en Córdoba, formado en Humanidades por las universidades de Sevilla y Madrid, una de las plumas más libres y certeras de la Espańa contemporánea: una voz singular, una garganta prestada a todo un pueblo con ansias de gritar bajo la mordaza y de vivir después del largo paréntesis de la dictadura. Y muy pocos escritores se pueden valer de este reconocimiento y de esta increíble popularidad que el pueblo español le concede a Antonio Gala ${ }^{3}$.

Pero no es el fervor de su público, sino el examen de la crítica lo que nos concierne ahora. El trabajo que se expondrá a continuación supone el establecimiento de un estado de la cuestión. Teniendo en cuenta que Gala ha clausurado su actividad literaria, hemos creído pertinente valorar el corpus científico derivado de su obra. Para ello, ha sido fundamental la recopilación de la bibliografía y su profunda revisión. Gracias a esta labor pueden identificarse los expertos nacionales y extranjeros que han examinado las diversas facetas del autor como dramaturgo, poeta, novelista, articulista o guionista a lo largo de cinco décadas ${ }^{4}$. Asimismo, forma

2 Antonio Gala, Ahora hablaré de mí, Barcelona, Planeta, 2000, p. 288.

3 François Dubosquet, "Las tres fidelidades de Antonio Gala", Antonio Gala: eterno y de Cristal, pp. 181-187 (p. 181).

4 Para la consulta de la bibliografía completa de Antonio Gala, véase Clara Cobo 
parte de nuestro objetivo esclarecer las principales líneas de investigación que orbitan en torno a la extensa y diversa producción del cordobés. Ante la imposibilidad de reflejarlas en su totalidad y de explicarlas de forma detallada, se detallarán los conceptos y los aspectos esenciales que han prevalecido, dado el acuerdo de los expertos. Así, esta panorámica focalizará objetos tan diversos como la temática, la construcción de personajes y espacios literarios, la hibridación genérica, el tratamiento de la intertextualidad o la dimensión social, histórica y política de su obra, entre otros. Esperamos que esta aproximación, no solo al universo literario del escritor, sino también al legado científico derivado del mismo, se comprenda como un mapa sobre el que trazar nuevas vías de pesquisa ${ }^{5}$.

\section{Antonio Gala, dramaturgo}

Desde que se estrenara su primera obra, Los verdes campos del Edén (1963), Gala, quien nunca se consideró un hombre de teatro, encauzó sus inquietudes poéticas a través de este género. De hecho, tal y como el autor ha reconocido en más de una ocasión, la idea de esta pieza dramática ya latía en su primer libro de poemas, Enemigo intimo (1960). Gala se acerca al teatro, como apunta Fausto Díaz Padilla en la introducción de Obras escogidas, porque "la misión del poeta es esa misma: tocar los corazones y las mentes de sus personajes para que reaccionen positivamente ante el mara-

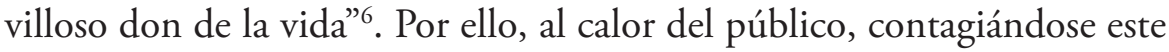

Guijarro, "Antonio Gala: Bibliografía completa”, en Antonio Gala: Eterno y de Cristal, ed. cit., pp. 205-211.

5 La bibliografía completa derivada de la investigación de la obra de Antonio Gala puede consultarse en: Ana Padilla Mangas y Clara Cobo Guijarro, "Bibliografía completa sobre la obra de Antonio Gala", Boletin de la Real Academia de Ciencias, Bellas Letras y Nobles Artes de Córdoba, CLXVII (2018), pp. 381-404.

6 Fausto Díaz Padilla, "Prólogo" a Antonio Gala, Obras escogidas, Madrid, Aguilar, 1981, pp. VII-CLV (p. CXLIV). Díaz Padilla realizó su tesis doctoral (1975) sobre el teatro de Antonio Gala. En 1981 se encargó de la primera recopilación de sus obras dramáticas (la antología incluye: Los verdes campos del Edén; El caracol en el espejo; El sol en el hormiguero; Noviembre y un poco de yerba; Spain's strip-tease; Los buenos días perdidos; Anillos para una dama; Las citaras colgadas de los árboles; ;Suerte, campeón!; ¿Por qué corres, Ulises?; Petra Regalada y La vieja señorita del Paraíso). Véase la relación completa de las obras de teatro en Clara Cobo Guijarro, op. cit., pp. 206-208. 
de la realidad de los personajes, la escritura dramática de Gala alcanzaba su potencial significado. El teatro de Antonio Gala es poético - argumenta Andrés Amorós - "porque intenta dar expresión estética adecuada y permanente a las fuerzas básicas, los instintos primarios, las intuiciones esenciales del ser humano; es decir, lo que nos identifica y nos une, no lo que nos separa"'. De ahí que este género haya sido el más aplaudido por el público y el más celebrado por la crítica, pues en su teatro los grandes temas humanos, encarnados en sus personajes, fluyen libremente, canalizando la alta cultura y la cultura popular.

Su recorrido en el género dramático ha sido objeto de reflexión en más de 150 trabajos académicos en España y en el extranjero. Muchos de ellos se han publicado como estudios preliminares, introducciones o prólogos en las ediciones de sus textos teatrales ${ }^{8}$. Así, los primeros que aparecieron

7 Andrés Amorós, "El teatro de los poetas", en Antonio Gala y el arte de la palabra, coord. Ana Padilla Mangas, Córdoba, Universidad de Córdoba, 2011, pp. 69-86 (p. 76).

8 Los principales investigadores de la obra de Antonio Gala han editado, anotado y/o prologado sus obras teatrales. Véanse, entre otros (ordenados por fecha): Federico Carlos Sainz de Robles, "Prólogo: breve reseña de una temporada teatral (19631964)", en Antonio Gala, Los verdes campos del edén; Miguel Mihura, La bella Dorotea; y Alejandro Casona, Los árboles mueren de pie (Teatro Español 1963-64), Madrid, Aguilar, 1965, pp. 11-29 [incluye: "Autocrítica" (p. 183) y "Críticas" (pp. 183-189)]; José Monleón, Alejandro Casona y José Ma Rodríguez, "Juicios sobre Antonio Gala”, en Antonio Gala, El caracol en el espejo, El sol en el hormiguero y Noviembre y un poco de yerba, Madrid, Taurus, 1970, p. 9-51 [Incluye: "La imagen de Antonio Gala" (pp. 51-87); "La obra de Antonio Gala" pp. 87-95, y "La crítica teatral española ante Gala" (pp. 95-121)]; Federico Carlos Sainz de Robles, "Prólogo", en Antonio Gala, Los buenos días perdidos; Ana Diosdado, El okapi; Jaime Salom, Tiempo de espadas; José Fernando Dicenta, La jaula; y, Enrique Llovet, Sócrates (Teatro español 1972-1973), Madrid, Aguilar, 1974, pp. IX-XXXVI [incluye: "Antecrítica" (p. 217) y "Críticas" (pp. 218-224)]; Enrique Llovet, "Prólogo", en Antonio Gala, Las citaras colgadas de los árboles y ¿Por qué corres, Ulises?, Madrid, Espasa-Calpe, 1977, pp. 9-35; Carmen Díaz Castañón, "Estudio preliminar", en Antonio Gala, Trilogía de la libertad: Petra regalada, La vieja señorita del paraíso y El cementerio de los pájaros, Madrid, EspasaCalpe, 1981 [incluye: "Introducción” (pp. 11-14); "Petra Regalada” (pp. 15-26); “La vieja señorita del paraíso" (pp. 27-54); "El cementerio de los pájaros" (pp. 55-70), y "Final" (pp. 71-80)]; Phyllis Zatlin, "Estudio previo", en Antonio Gala, Noviembre y un poco de yerba y Petra Regalada, Madrid, Cátedra, 1983, pp. 11-74 [incluye: "Nota preliminar" (pp. 11-12); "Crono-biografía de Antonio Gala" (pp. 13-28), y "El teatro de Antonio Gala" (pp. 29-74)]; Hazel Cazorla, "Introducción”, en Antonio Gala, Los 
suponen las primeras aproximaciones a la obra dramática de Gala. En estas colaboraciones, así como en el resto de publicaciones científicas, no ha pasado inadvertida la presencia del primer ámbito de estudio al que nos referiremos.

Convencido de que el paisaje hace a la figura, Andalucía ha sido objeto de hermosas reflexiones y de sinceros homenajes, pero también se ha erigido como escenario al servicio de sus argumentos y como cartografía de su expresión poética. Las antologías de Ana Padilla Mangas (Córdoba de Gala, 1993) y Carmen Díaz Castañón (Andaluz, 1994) son prueba de ello. De acuerdo con Padilla Mangas, en su recreación de los espacios del sur, Gala "sabe captar la realidad, aprehender el ensueńo, rememorar el pasado y sentir el presente. Y es que le gusta su tierra, su forma de entender la vida, su peculiar humor, su manera de hablar, su soledad; ahora bien, es precisamente esta pasión la que le conduce a una actitud crítica,

verdes campos del Edén, Salamanca, Almar, 1983, pp. 13-38; Carmen Díaz Castañón, "El teatro de Antonio Gala", en Antonio Gala, Samarkanda y El hotelito, Madrid, Espasa-Calpe, 1985, pp. 9-28; José Romera Castillo, "Prólogo", en Antonio Gala, Los verdes campos del Edén y El cementerio de los pájaros, Barcelona, Plaza \& Janés, 1986a, pp. 15-115; Andrés Amorós, "Introducción biográfica y crítica”, en Antonio Gala, Los buenos días perdidos y Anillos para una dama, Madrid, Castalia, 1987, pp. 9-117; José María Areilza y Javier Sábada, "Prólogo", en Antonio Gala, Séneca o el beneficio de la duda, Madrid, Espasa-Calpe, 1987, pp. 9-46. [incluye: Prólogo de José Ma Areilza (pp. 9-16) y Prólogo de Javier Sábada (pp. 17-46)]; José Romera Castillo, "Prólogo", en Antonio Gala, Carmen Carmen, Madrid, Espasa-Calpe, 1988, pp. 9-44; José Romera Castillo, "Prólogo", en Antonio Gala, Cristóbal Colón, Madrid, Espasa-Calpe, 1990, pp. 9-65; Phyllis Zatlin, "Introducción”, en Antonio Gala, Los verdes campos del Edén y Los buenos días perdidos, Madrid, Espasa-Calpe, 1994, pp. 9-43; Isabel Martínez Moreno, "Prólogo", en Antonio Gala, Los bellos durmientes, Madrid, Espasa-Calpe, 1994, pp. 9-49; Carmen Díaz Castañón, "Prólogo", en Antonio Gala, Samarkanda y Los bellos durmientes, Barcelona, Planeta-De Agostini, 1999, pp. 9-32; José Romera Castillo, "Prólogo", en Antonio Gala, Las manzanas del viernes, Madrid, Espasa-Calpe, 1999, pp. IX-XXVII; Carmen Díaz Castañón y Andrés Peláez, "Prólogo", en Antonio Gala, Café cantante y El hotelito, Barcelona, Planeta-De Agostini, 1999, pp. 7-23/ pp. 137-141; José Romera Castillo, Ana Padilla Mangas y Robert Muro, "Análisis crítico, biografía y bibliografía, y presentación y álbum de fotografías", en Antonio Gala, El caracol en el espejo, Madrid, Sociedad General de Autores y Editores, 2003, pp. 99-116; y Andrés Peláez, "Prólogo", en Antonio Gala, Inés desabrochada, Madrid, Espasa-Calpe, 2003, pp. IX-XXIII. Véase el listado completo de primeras ediciones y otras ediciones con prólogos y notas en Clara Cobo Guijarro, op. cit, pp. 206-208. 
de lucha, de denuncia [...]"9.

La esencia andaluza impregna el conjunto de su obra. En las novelas de Gala, publicadas a partir de 1990, las ciudades andaluzas se consolidan como espacios referenciales: El manuscrito carmesi (Granada/Córdoba); Más allá del jardín (Sevilla); La regla de tres (finca "La meridiana», provincia de Málaga); Las afueras de Dios (Córdoba); El imposible olvido (Málaga/Granada), y Los papeles de agua (Alhaurín el Grande). En su poesía destacan los poemas de Testamento andaluz (1985), inspirados por espacios emblemáticos de esta tierra, también presente en los poemarios Enemigo intimo (1960), Los sonetos de la Zubia (1966-1987) y Poemas cordobeses (1994), así como en otros textos poéticos, como "La deshora" (1962) y "Meditación en Queronea" (1965). Asimismo, al margen de los géneros literarios, se han de destacar el discurso pronunciado por Gala en la apertura del Congreso de Cultura Andaluza, pronunciado en la Mezquita-Catedral de Córdoba el 2 de abril de 1978, y sus palabras en el acto de su investidura como doctor honoris causa de la Universidad de Córdoba en 1982. La multiplicidad de matices que forman la esencia andaluza también le sirvieron a Gala para componer varios capítulos de su serie televisiva Paisaje con figuras: Averroes, Almanzor, Gonzalo Fernández de Córdoba, Murillo, Mariana Pineda o Antonio Machado, entre otros ${ }^{10}$.

Pero, ciñéndonos al marco de los estudios críticos de teatro, la figura más representativa es la protagonista de Carmen Carmen (1988), obra de teatro musical estrenada y publicada en 1988. El personaje que interpretó Concha Velasco sobre las tablas está inspirado en el homónimo de Prosper Mérimée (1845). Para la actualización de este arquetipo universal

9 Ana Padilla Mangas, "Prólogo", en Antonio Gala, Córdoba de Gala, coord. Ana Padilla Mangas, Córdoba, Almuzara, 2017, pp. 13-19 (p. 14). Córdoba de Gala (1993) ha sido reeditado en 2017 (Almuzara) incluyendo un nuevo apartado, "Córdoba compartida", en el que Padilla Mangas añade los textos de Antonio Gala escritos expresamente para los jóvenes creadores residentes en su Fundación Antonio Gala para Jóvenes Creadores ubicada en Córdoba. Estos proceden de los catálogos editados anualmente por la Fundación.

10 Véase Antonio Gala, Paisaje andaluz con figuras (Vol. I y Vol. II), Granada, Biblioteca de Cultura Andaluza, 1984. Asimismo, para el estudio de sus reflexiones en prensa sobre Andalucía véase Antonio Gala, Córdoba de Gala, pp. 332-333; y Antonio Gala, Andaluz, ed. Carmen Díaz Castañón, Madrid, Espasa-Calpe, 1994, pp. 487-495. 
Gala ideó una Carmen que "revienta de amor por doquier y que se rebela contra una sociedad ortopédica y falsa que la rodea"11. Para ello, siguiendo a Romera Castillo — a cargo del prólogo de la edición de la obra-, se precisa redimir el tópico y efectuar una desmitificación ${ }^{12}$. A propósito de esta cuestión, Carmen Pujante Segura aseveraba recientemente que "el autor español acomete su desmitificación en una obra sobre la que opera el trasvase genérico y tonal, hacia el teatro y hacia lo cómico con toques satíricos, valiéndose de ciertas convenciones del teatro español de la década de 1980 postransicionales, años que estaban cargados de significación social e ideológica [...]"13. Carmen Carmen emerge como paradigma de las desmitificaciones de Gala, de las que nos ocuparemos más adelante ${ }^{14}$.

En otro orden, cabe destacar en el conjunto de su teatro el legado de la Córdoba romana y califal. En palabras de Hazel Cazorla, el andaluz asumió la herencia de una tierra que se refleja en él mismo y en su escritura dramática:

Algo hay de romano y moro que comparte nuestro autor con esta antigua tierra: una elegancia natural, una seriedad castiza, un aprecio de la belleza y un lenguaje chispeante y profundo, capaz de saltar de lo más culto a lo más popular sin afectación ninguna. Sería lógico

11 José Romera Castillo, "Francia en el teatro de Antonio Gala", en Imágenes de Francia en las letras hispánicas, ed. Francisco Lafarga, Barcelona, PPU, 1989, pp. 191-198 (p. 193).

12 José Romera Castillo, "Prólogo", en Antonio Gala, Carmen Carmen, ed. cit., p. 35.

13 Carmen Pujante Segura, "El mito de Carmen a finales del siglo XX: desmitificación o remitificación”, en Actas del XVII Simposio de la Sociedad Española de Literatura General y Comparada, coords. Montserrat Cots Vicente y Antonio Monegal, Madrid, Universitat Pompeu Fabra/SELGyC, 2010, vol. I, pp. 379-390 (p. 380).

14 A propósito de la vinculación de Carmen Carmen con el mito y la tradición andaluza, véase también Hazel Cazorla, "La tradición pasional andaluza en Carmen Carmen de Antonio Gala", en De lo particular a lo universal: el teatro español del siglo XX y su contexto, coord. John P. Gabriele, Madrid, Iberoamericana, 1994, pp. 143-150; Alberto Egea Fernández-Montesinos, "Carmen Carmen de Antonio Gala, pos-costumbrismo y des-orientalización de los mitos andaluces", Revista de Estudios Hispánicos, XXXVII, 1 (2003), pp. 31-48; y Virginia Guarinos, "Carmen: Puro teatro. Granés, Madariaga, Gala y Távora”, en Carmen global. El mito en las artes y en los medios audiovisuales, eds. Rafael Utrera Macías y Virginia Guarinos, Sevilla, Universidad de Sevilla, 2010, pp. 251-275 (pp. 265-268). 
que su teatro, en forma y espíritu, también le debiera a esta herencia andaluza su perfil característico ${ }^{15}$.

En esta revisión Cazorla examina la tradición clasicista mediterránea y arábigo-andaluza no solo a través de Séneca o el beneficio de la duda (1987) - de la que afirma la existencia de un paralelismo dramático entre su escenografía y la mezquita cordobesa—, sino también a través de Las manzanas del viernes (1999), cuya protagonista, Orosia, habrá de enfrentar la pasión amorosa como la Fedra senequista. En opinión de la experta, "la destrucción de una mujer a manos de su propia pasión es tema mítico de origen greco-latino; también es clásica la estructura de esta obra en su conformidad con la de las normas de simetría, orden y lógica"16.

Del mismo modo, la escenografía de esta propuesta teatral también recuerda, según la autora, a la arquitectura de la Córdoba califal. La "metáfora del mirador", frontera de los mundos interno y externo del ser humano, se recrea en Las manzanas del viernes; no obstante, con anterioridad había formado parte del decorado de Petra regalada (1980), cuyo "resultado fatal" queda ubicado en el balcón ${ }^{17}$. Así, Cazorla, abordando las dimensiones histórica, sociológica y artística de la Córdoba hispanoárabe, desarrolla las concomitancias pertinentes no solo en las obras mencionadas, sino también en muchas otras, como Los verdes campos del Edén (1964), El caracol en el espejo (1970) o La vieja señorita del paraíso (1981). En definitiva, la herencia cultural de Andalucía es, suscribiendo las palabras de Díaz Castañón, múltiple, inasible e inagotable ${ }^{18}$. Y en su teatro, la historia y la intrahistoria de este territorio sirven de inspiración para sus tramas, pero también suponen el motor de la representación, pues todo sobre el escenario cumple el compromiso vital del autor con esa tierra.

En consonancia con las anteriores reflexiones se infiere otro fenómeno destacado por otras estudiosas y característico de la producción de Gala:

15 Hazel Cazorla, "El legado de la Córdoba «romana y mora» en el teatro de Antonio Gala”, en Antonio Gala y el arte de la palabra, coord. Ana Padilla Mangas, Córdoba, Universidad de Córdoba, 2011, pp. 87-103 (p. 87).

16 Ibidem, pp. 93-94.

17 Ibidem, p. 97.

18 Carmen Díaz Castañón, “Introducción”, en Antonio Gala, Andaluz, pp. 9-43 (p. 23). 
el desdoblamiento del espacio. En consecuencia, los espacios referenciales adquieren una importante dimensión simbólica, que ha sido recreada en Los verdes campos del Edén (1963) con el panteón; en Noviembre y un poco de yerba (1967), con el sótano; en la celda de Petra regalada (1980); en el café de La vieja señorita del paraíso (1980); o en la capilla de Los buenos días perdidos (1972). Estos son lugares de soledad y resignación que se transformarán al mismo tiempo que los personajes que los habitan, quienes anhelan, no sin inmovilismo, encontrar en sí mismos un espacio para el cambio y la redención.

Sus protagonistas se hallan, como reza uno de los títulos de Cazorla, en "cárceles de la conciencia”: "[...] El ser humano, en las obras galianas, es prisionero de su propia mediocridad, de su auto-decepción, sus propias mentiras y su fingimiento, de su pasividad cobarde frente a la aventura de la vida auténtica" ${ }^{19}$. En esta línea, Isabel Martínez Moreno añadía recientemente que, leyendo su teatro, nos dejamos guiar “[...] rumbo a escenarios de soledad; también, según está escrito en sus páginas, rumbo a la anatomía de las almas solas y, al final, en un apéndice idílico, hacia la geografía de los sueños" ${ }^{20}$. Esta aguarda en el territorio del ideal, el paraíso perdido, un nuevo espacio alegórico que en las creaciones de Gala puede materializarse o disolverse junto con las ilusiones de sus personajes. Este concepto fue previamente tratado por Phyllis Zatlin, José Romera Castillo y, más tarde, por Isabel Martínez Moreno en un extenso libro donde analiza esta cuestión de forma pormenorizada ${ }^{21}$. Mención aparte merece asimismo el interés de los estudiosos por la revisión de los mitos y su consecuente «desmitificación», como ya adelantamos al referirnos a

19 Hazel Cazorla, "Cárceles de la conciencia y fugas pasionales: espacios psíquicos en dos estrenos recientes de Antonio Buero Vallejo y Antonio Gala (Las trampas del azar y Los bellos durmientes)", en Entre actos: diálogos sobre Teatro Español entre siglos, ed. Martha T. Halsey y Phyllis Zatlin, University Park (Pennsylvania), Estreno, 1999, pp. 185-193 (p. 190).

20 Isabel Martínez Moreno, "El teatro de Antonio Gala: escenarios de soledad, espacios para un sueño", en Antonio Gala y el arte de la palabra, pp. 137-172 (p. 148).

21 Phyllis Zatlin Boring, "The Theatre of Antonio Gala: In Search of Paradise", Kentucky Romance Quartely, XXIV, 2 (1977), pp. 175-183; José Romera Castillo, "Prólogo", en Antonio Gala, Los verdes campos del Edén y El cementerio de los pájaros, pp. 15-115 (p. 98); e Isabel Martínez Moreno, Antonio Gala. El paraíso perdido, Madrid, CSIC, 1994. 
Carmen Carmen. ¿Por qué corres, Ulises? (1975), su pieza más representada y traducida, ha sido la más ampliamente estudiada en este contexto ${ }^{22}$. El examen de su condición hipertextual, así como de la reescritura del mito y la reconstrucción de los personajes de La Odisea han sido evaluados en multitud de estudios ${ }^{23}$. Como decíamos, no es tanto el mito el hilo con-

22 No obstante, el concepto de desmitificación aparece por primera vez en un estudio de Hazel Cazorla sobre Anillos para una dama, obra publicada en 1974 [Hazel Cazorla, "Antonio Gala y la desmitificación de España: Los valores alegóricos de Anillos para una dama", Estreno: cuadernos del teatro español contemporáneo, IV, 2 (1978), pp. 13-15]. A propósito del uso de esta noción en muchas de las obras del autor cordobés, se recomienda la lectura del citado prólogo de Romera Castillo a Carmen Carmen (José Romera Castillo, op. cit., pp. 9-44).

23 Son muchos los investigadores que han tratado la pervivencia del mito clásico en el teatro español contemporáneo, incluyendo, por supuesto, el análisis de ¿Por qué corres, Ulises? El último trabajo sobre esta cuestión se deriva de una tesis doctoral (Alessandra Procopio, $E l$ mito de Ulises y Penélope en el teatro español contemporáneo, Madrid, Fundamentos, 2018). En esta línea, José C. Paulino establece una valiosa división de las distintas aproximaciones al mito en el teatro posterior a la posguerra [José C. Paulino, "Ulises en el teatro español contemporáneo. Una revisión panorámica”, Anales de la literatura española contemporánea, XIX, 3 (1994), pp. 327-342 (p. 333-334)]. Por su parte, Fernando García Romero, comparando otras reescrituras de esta figura en la época contemporánea, comenta la caracterización "patética y algo grotesca" de Ulises en la propuesta de Gala [Fernando García Romero, "El mito de Ulises en el teatro español del siglo XX”, CFC: egi, IX (1999), pp. 281-303 (p. 289)]. De una propuesta anterior del mismo autor, cabe señalar —en consonancia con las reflexiones del dramaturgo cordobés- el retrato de un Ulises de la posguerra, un Ulises 75 que desafía la figuración del Ulises clásico [Fernando García Romero, "El mito de Ulises en el teatro español del siglo XX", Cuadernos de Filología Clásica: estudios griegos e indoeuropeos, XVIII (1983), pp. $361-382$ (p.289)]. También se ocupará García Romero, entre otros temas, de la reescritura de Penélope, quien, como la Jimena de Anillos para una dama, no oculta sus propias pasiones ni su personal concepción de los roles matrimoniales. Zatlin trató previamente estas cuestiones en los ańos ochenta: "En la comedia de Gala la fidelidad de Penélope ante el abandono de Ulises es un mito, así como la justificación de la guerra misma [...]. Ni Jimena [Anillos para una dama] ni Penélope están dispuestas a actuar dentro de tal farsa. Su rebeldía ante el estereotipo sexual tiene, por eso, su importancia política, incluso para la época actual" (Phyllis Zatlin Boring, "Estudio previo", en Antonio Gala, Noviembre y un poco de yerba y Petra Regalada, p. 55). No obstante, tal y como apuntara García Romero décadas después, "esta Penélope de A. Gala representa la estabilidad para su Ulises, aunque ello signifique el aburrimiento y la pérdida de todas las ilusiones, su último refugio para soportar la vejez" [Fernando García Romero, "Pervivencia de Penélope", en El perfil de les ombres. El teatre clàssic al 
ductor de estos trabajos como los recursos de desmitificación utilizados por Antonio Gala en esta obra, cuyo alcance se hace efectivo en otros aspectos de su producción dramática. Puede afirmarse con Zatlin que "a Antonio Gala le encanta desenmascarar relevantes figuras históricas a la

marc de la cultura grega $i$ la sua pervivència dins la cultura occidental, coords. Carmen Morenilla Talens y Francesco de Martino, Bari, Levante Editori, 2002, pp. 187-204 (p. 190)]. Sin embargo, como sostiene Ramiro González Delgado, la Penélope de Gala es libertina y no esconde en absoluto su adulterio [Ramiro González Delgado, "¿Casta, libertina o feminista?: Penélope en el teatro español contemporáneo (II)”, La ratonera: Revista asturiana de teatro XIII (septiembre 2005), pp. 106-113 (p. 108)]. El estudio de los personajes femeninos de esta propuesta teatral es pormenorizado en los trabajos de Padilla Mangas, desde una perspectiva lingüística, y de Lucía Rodríguez Olay, en el contexto de los estudios de género (Ana Padilla Mangas, Tipología dramática en la obra de Antonio Gala, Córdoba, Diputación Provincial de Córdoba, 1985, pp. 71-166; Lucía Rodríguez Olay, Personajes femeninos en el teatro de Antonio Gala: una perspectiva de género, Madrid, Editorial Académica Española, 2011, pp. 148-168). En otro orden de cosas, Carmen María López destaca las conexiones intertextuales en la creación de Gala. Sirvan de ejemplo la presencia del Canto VI de La Odisea (Naufragio de Ulises y encuentro con Nausica) como marco de desarrollo de la desmitificación de los personajes; las evocaciones transversales del Canto V, a través del cual se manifiesta directamente una cita del relato homérico en dicho punto; y, asimismo, más adelante la alusión al Canto IX [Carmen María López López, "Odiseo a través de la parodia. Desmitificación e ironía de una Ítaca nostálgica en Prometeo de Pérez de Ayala y ¿Por qué corres, Ulises? de Gala”, Panta Rei: Revista Digital de Ciencia y Didáctica de la Historia (2014), pp. 71-96 (p. 80) «https:// www.um.es/cepoat/pantarei/catalogo/pantarei2014/» (Consulta: 13/01/2019)]. En otro de sus estudios, López se reafirma en el estudio de la obra de Gala a la luz de un punto de vista lúdico [Carmen María López López, "Hacia una lectura paródica del mito: caída y descreimiento del héroe en ¿Por qué corres, Ulises? de Antonio Gala", Cuadernos de Aleph, VII (2015), pp. 97-116 (p. 102-108) «https://dialnet.unirioja.es/revista/19647/A/2015» (Consulta: 13/01/2019)]. Los procesos de (re)mitificación/desmitificación del héroe griego también ocupan buena parte de la investigación sobre esta obra [Elisabeth Rogers, "Myth, Man and Exile in El retorno de and ¿Por qué corres Ulises?", Anales de la literatura española contemporánea. IX, 1-3 (1984), pp. 117-130; José Romera Castillo, "Prólogo", en Antonio Gala, Carmen Carmen, pp. 9-44; Victoria Martínez Robertson, "Antonio Gala’s ¿Por qué corres, Ulises?: Form in Search of Content”, Anales de la literatura española contemporánea, XVII, 1-3 (1992), pp. 221-228; e Isabel Martínez Moreno, Antonio Gala. El paraíso perdido, pp. 371-407]. Más recientes son los citados trabajos de Carmen María López (2014 y 2015) y el monográfico de Laura Arroyo, del que destacamos especialmente la segunda parte del mismo (Laura Arroyo Martínez, La desmitificación de Ulises en el teatro de Antonio Gala. Confluencia, Madrid, Ediciones Clásicas, 2010). 
vez que sigue otra tendencia: la creación de mitos originales para luego desmitificarlos" 24 . El elemento desmitificador queda patente en la revisión de figuras históricas, populares, religiosas y literarias, como puede comprobarse en Carmen Carmen (1988) a través de la recreación del mito popular y literario español; en Las citaras colgadas de los árboles (1974) y en la ópera Cristóbal Colón (1989), con la relectura de la conquista de América; en Anillos para una dama (1973), que distorsiona el heroísmo del Cid y empodera a Dońa Jimena; o en Inés desabrochada (2003), donde de nuevo se invierte la jerarquía de los protagonistas, así como de los roles sexuales, para mostrar una Inés renovada respecto a la de José Zorrilla.

La desmitificación de estas figuras se plantea en consonancia con una reflexión sociopolítica del momento actual. En efecto, en varios de los primeros acercamientos al teatro del cordobés ya se aborda el estudio de los motivos políticos ${ }^{25}$. En opinión de Zatlin, "con Noviembre y un poco de yerba, Gala empieza una serie en que las referencias a la realidad española contemporánea dejan de ser oblicuas" ${ }^{26}$. Se distinguen entonces dos vertientes fieles a un mismo objetivo. Por un lado, las obras históricas, cuya explicación permite establecer un fuerte anclaje con el presente y, por otro, las obras contemporáneas, que emergen como instrumento desmitificador de la etapa franquista y post-franquista ${ }^{27}$.

24 Phyllis Zatlin, "Variantes de desmitificación en la obra de Antonio Gala", Antonio Gala y el arte de la palabra, pp. 239-256 (p. 246).

25 Sobre estas primeras propuestas, véase: David M. Kirsner, "The Theater and Politics of Antonio Gala", Hispanic Literature and Politics, Indiana, Indiana University of Pennsylvania, 1977, pp. 241-250; y Carmen Díaz Castañón, "Acercamiento al teatro político de Antonio Gala”, Los cuadernos del Norte, III, 12 (1982), pp. 26-39.

26 Phyllis Zatlin, "Estudio previo", en Antonio Gala, Noviembre y un poco de yerba y Petra Regalada, p. 44.

27 A propósito de los dramas históricos de Gala, véanse también los apartados que distingue Romera Castillo en un excelente estudio (José Romera Castillo, "Sobre el teatro con referencias históricas de Antonio Gala", en Antonio Gala y el arte de la palabra, pp. 209-237). Para un mayor acercamiento a la obra de Gala desde esta perspectiva véase José Romera Castillo, Con Antonio Gala (estudios sobre su obra), Madrid, UNED, 1996. En este volumen no solo examina su teatro, sino también otros aspectos de su labor como poeta, cronista o guionista. Por último, en los últimos tiempos, el investigador ha estudiado la música en el conjunto del corpus de Gala, con especial hincapié en Spain's striptease, jSuerte, campéon!, Carmen Carmen, La truhana y la ópera Cristobal Colón. Sobre esta cuestión puede consultarse José Romera 
Como apuntábamos, ambas distinciones convergen en un fin común: "Del pasado no hay una sola interpretación. La interpretación oficial ha sido más mito que realidad. Hay que desmitificar el pasado para entender el presente" ${ }^{28}$. Sobre Los verdes campos del Edén (1963) el propio Gala confiesa: "Su gran ironía no es que pasara en un cementerio, sino que arriba (fuera, en el mundo exterior) no se podía vivir. Era mi sátira antifranquista" ${ }^{29}$. El mismo espíritu comparte El sol en el hormiguero (1966), que fue retirada de la cartelera dos semanas después del estreno. O Los buenos dias perdidos (1972), que, según explica Romera Castillo, presenta un "fondo metafórico" de la sociedad de posguerra: "Los verdaderos protagonistas de la historia dramática son los dos poderes que siempre han ejercido su coerción sobre el pueblo y la historia española: el militar y el eclesiástico"30. Asimismo, a la luz de Anillos para una dama (1973), Cazorla recuerda que "nos ofrece una intuición acerca de la situación post-franquista del país" ${ }^{31}$, y, tiempo después, Zatlin añade sobre la protagonista de la obra citada que “[...] representa la Espańa que quiere renovarse" 32 .

Castillo, "Antonio Gala y la música", en Antonio Gala: eterno y de Cristal, pp. 143149 (asimismo, en este marco, resulta relevante su ponencia inédita en el II Congreso Internacional "Antonio Gala: de la palabra arte»).

28 Phyllis Zatlin, "Estudio previo", en Antonio Gala, Noviembre y un poco de yerba y Petra Regalada, p. 45.

29 César Oliva, Antonio Gala. El teatro que yo escribo, Sevilla, Universidad Internacional de Andalucía, 2008, p. 49. En este monólogo de Gala — comentado y editado por Oliva - se hace referencia a la censura de algunas de las obras. El sol en el hormiguero, "texto con un sentido político más profundo que el anterior", fue prohibida a los quince días del estreno (ibidem, p. 58). Asimismo, jSuerte, campeón! fue censurada en 1973. A pesar de sus problemas con la censura, Gala añade en el libro de Oliva: "[...] Nunca he escrito autocensurándome. He preferido que me corten a que me corte yo. Nunca he sido escandaloso y de decir tacos y de decir insultos, ni de ponerme violento o atacar con furia a un régimen. Todo lo he hecho de una manera más irónica, más sonriente, más eficaz, me parece, porque una persona que grita ya empieza a perder la razón en cuanto grita" (ibidem, pp. 66-67).

30 José Romera Castillo, "Prólogo", en Antonio Gala, Carmen Carmen, ed. cit., p. 17.

31 Hazel Cazorla, "Antonio Gala y la desmitificación de España: los valores alegóricos de Anillos para una dama", p. 13.

32 Phyllis Zatlin Boring, "Estudio previo", en Antonio Gala, Noviembre y un poco de yerba y Petra Regalada, p. 55. 
Tras la muerte de Franco, Gala permanecerá en silencio algún tiempo. Cinco años más tarde verá la luz la Trilogía de la libertad (Petra regalada, La vieja señorita del paraíso y El cementerio de los pájaros) ${ }^{33}$. La primera es la historia de Petra, una prostituta que, sometida por hombres poderosos, mantiene vivas sus esperanzas en Mario, el opositor al régimen. Sin embargo, para desgracia de la protagonista, Mario mantendrá el orden preestablecido. En palabras de Romera Castillo, "la obra contenía un sentido casi profético. El PSOE llegaría al poder dos años después y el cambio, según Gala, se iba a notar poco [...]"34. En la misma línea, el investigador considera La vieja señorita del paraiso (1980) "una diatriba contra la OTAN [...]: La vieja señorita, Adelaida, se refugia en el café «El Paraíso» en espera de su amor, se opone a la instalación de una fábrica de armas — trasunto de la OTAN_ - y resiste allí hasta el final" 35 . La última de estas obras, El cementerio de los pájaros (1982), refleja el intento de golpe de estado de $1981^{36}$. Décadas más tarde, Gala admitiría que la trilogía “es toda una crónica de la transición” ${ }^{37}$. Pero ni siquiera en estas piezas dramáticas renuncia Gala a las constantes de su teatro:

Yo he escrito siempre la misma obra, con los mismos ingredientes: un escenario oprimente, extrańamente oscuro, alguien que ha perdido la libertad, un factor desencadenante y las situaciones que a continuación se producen. Y luego eso se construye sobre dos rieles, que son la justicia, esa justicia absoluta que debe permitir a todos los hombres que se cumplan; y la esperanza, que muchas veces no está en mi obra pero que salpica al espectador y le recomienda que salve en la vida lo que en el escenario no ha podido ser salvado ${ }^{38}$.

33 Sobre la Trilogía de la libertad véase también Carmen Díaz Castañón, "Estudio preliminar", en Antonio Gala, Trilogía de la libertad: Petra regalada, La vieja señorita del paraíso y El cementerio de los pájaros, pp. 15-70.

34 José Romera Castillo, "Prólogo", en Antonio Gala, Carmen Carmen, p. 24.

35 Ibidem, p. 25.

36 Ibidem, p. 26.

37 César Oliva, op. cit., pp. 91-92.

38 Palabras de Gala en José Romera Castillo, "Prólogo", en Antonio Gala, Los verdes campos del Edén y El cementerio de los pájaros, pp. 97-98. 
Si con Noviembre y un poco de hierba la alegoría política dejaba de ser pura insinuación, con Petra regalada —y, por extensión, con la Trilogía de la libertad- el autor cordobés pone fin a la dimensión histórico-política de su obra dramática ${ }^{39}$. No obstante, aún habrá de estrenarse El hotelito (1985), una historia española, tal y como Gala la definió, que, si bien hace referencia al Estado de las Autonomías a través de sus cinco protagonistas, estas portarán asimismo un sentido alegórico de la historia de España ${ }^{40}$. En la que será la última etapa de su teatro, las referencias históricas ceden el testigo a las literarias, sobre las que también ha de efectuarse el proceso de desmitificación. A los ejemplos citados de Carmen Carmen (1988), Las manzanas del viernes (1999) e Inés desabrochada (2003) se ha de sumar La truhana (1992), obra de teatro musical, que supone una celebración de la picaresca y la literatura carnavalesca ${ }^{41}$. Como ha podido comprobarse, en el teatro de Gala la historia de Espańa y, en su seno, la historia literaria española sirven de plataforma para que el autor reflexione y muestre sin tapujos un proceso de ficcionalización que integra las facetas poética, transtextual, política y humanizadora de su teatro.

Por último, hemos de desarrollar otra clave que ha quedado implícita. El peso otorgado a las mujeres en estas obras. Las figuras femeninas de Gala han encarnado el correlato de los valores cultivados en su teatro. Nos referimos a las dicotomías de libertad/opresión, amor/desamor, esperanza/desesperanza, rebeldía/frustración, o memoria/olvido. "Antonio Gala tiene un concepto de escritura femenina similar al propuesto por Hélène Cixous — asevera Padilla Mangas_. Se trata de 'proclamar a la mujer como fuente de vida, poder y energía, y dar la bienvenida a un

39 Carmen Díaz Castañón, "El teatro de Antonio Gala”, en Antonio Gala, Samarkanda y El hotelito, p. 19. Hemos de indicar que aún no se había estrenado Carmen Carmen, obra que es continuadora de muchos de los patrones comunes de su teatro. Al respecto, véase José Romera Castillo, "Prólogo”, en Antonio Gala, Carmen Carmen, p. 25.

40 Carmen Díaz Castañón, "El teatro de Antonio Gala”, en Antonio Gala, Samarkanda y El hotelito, p. 27; y José Romera Castillo, "Sobre el teatro con referencias históricas de Antonio Gala”, p. 234.

41 Ana Padilla Mangas, "La truhana, un hito hacia la carnavalización en el mundo teatral de Antonio Gala", Boletín de la Real Academia de Ciencias, Bellas Letras y Nobles Artes de Córdoba, CXXIV (enero-junio 1993), pp. 101-115. 
lenguaje femenino' que derriba los esquemas binarios [...]"42. La fuerza transformadora y rupturista que aguarda en sus mujeres protagonistas se canaliza en diversos subaspectos que se antojan dignos objetos de estudio: la inteligencia emocional femenina, la rebeldía femenina o el heroísmo femenino. Son estas, en suma, facetas de una identidad común que se ha analizado principalmente mediante la perspectiva los estudios de géne$\mathrm{ro}^{43}$. No en vano - concluye Romera Castillo-, Gala se ha convertido "en uno de nuestros dramaturgos actuales que más han defendido el feminismo en nuestros escenarios" ${ }^{44}$. En efecto, Gala nunca ha ocultado su preferencia por los personajes femeninos:

Para actores no he escrito. La mujer me parece que está llena de expresividad; el hombre es más taciturno, actúa pero se explica; la mujer actúa y dice por qué actúa. Es mucho más expresiva. Y es más fácil encarnar una idea en una mujer que en un hombre. La libertad, la igualdad y la fraternidad siempre son mujeres. El amor lo expresa mucho mejor la mujer que el hombre. La mujer es más capaz de amor. Deja que entre el amor y la inunde, la queme, y abata los muros de su casa, mientras que el hombre tiene la casa guardadita ${ }^{45}$.

42 Ana Padilla Mangas, "De la actriz al personaje en el teatro de Antonio Gala", Boletín de la Real Academia de Ciencias, Bellas Letras y Nobles Artes de Córdoba, CXLVIII (2005), pp. 13-28 (p. 28).

43 Véanse, en esta línea, los siguientes trabajos: Elisabeth Rogers, "Role Constraints versus Self-Identity in La tejedora de sueños and Anillos para una dama", Modern Drama, XXVI, 3 (1983), pp. 310-319; Ana Padilla Mangas, "La inteligencia emocional femenina en la dramaturgia de Antonio Gala”, en Antonio Gala y el arte de la palabra, pp. 183-201; y Ma de las Nieves García Pareja, "La rebeldía femenina en la obra de Antonio Gala", en Antonio Gala y el arte de la palabra, pp. 129-136. Asimismo, anteriormente se mencionó la tesis doctoral de Rodríguez Olay (2011), donde queda reflejado su análisis de los personajes teatrales femeninos de Gala desde una perspectiva de género (2011). Por último, en el citado trabajo de Padilla Mangas (1985) se desentrañó la cosmovisión y funcionalidad dramática de los personajes femeninos secundarios de Gala centrándose en una figura fundamental en varios textos: la criada.

44 José Romera Castillo, "Sobre el teatro con referencias históricas de Antonio Gala", p. 256.

45 César Oliva, op. cit., p. 64. 
En consonancia, Andrés Peláez sostiene que "la mujer en el teatro de Gala ama por encima de todo y contra todo [...]. En ella el autor ha encontrado los símbolos y alegorías que han determinado la historia de la humanidad" 46 . Este rasgo característico —que nos sirve para cerrar el círculo que ha estructurado este apartado - es para Peláez continuador de la tradición dramática andaluza. Sin embargo, el amor y la libertad, sentimientos por excelencia del mundo interior de sus mujeres de ficción, serán explorados, con las posibilidades que le ofrecen las técnicas narrativas, en su novelística.

\section{Antonio Gala, novelista}

De las novelas que ha escrito, las dos primeras han sido las más ampliamente estudiadas: El manuscrito carmesí, Premio Planeta en 1990, y La pasión turca, publicada en 1993. La historia de Desideria Oliván, que abandona su vida y su matrimonio en Huesca para vivir en Estambul junto a su amado Yamam, inaugura el homenaje que Gala rendirá a las mujeres en su recorrido en este género ${ }^{47}$. El tema fundamental de estas obras protagonizadas por mujeres es el amor. Estas amantes — Gala siempre distingue entre amante y amado - comprenden el sentimiento amoroso como una vía de conocimiento. Bajo esta premisa mantiene Gala en su narrativa una de las constantes de sus personajes teatrales: descubrir la consciencia de sí mismos. Los personajes femeninos de sus novelas lo atestiguarán en el encuentro con el amado y en el acto de escritura, pues relatando lo que les acontece hallarán su mejor reflejo. Es justo ańadir que no es el amado, sino el amor, en todos sus paisajes soleados y oscuros, lo que arrastra a las protagonistas a una aventura vital.

De todas, es la historia de Desideria la más encarnizada. La mujer llevará hasta sus últimas consecuencias el amor que siente por el turco, agotán-

46 Andrés Peláez, "Algunas constantes en el teatro de Antonio Gala", en Antonio Gala y el arte de la palabra, pp. 203-209 (p. 205).

47 Las novelas protagonizadas por mujeres son La pasión turca (1993), Más allá del jardin (1995), Las afueras de Dios y Los papeles de agua (2008). Véase la relación completa de su obra narrativa (incluyendo relato y cuento) en Clara Cobo Guijarro, "Antonio Gala: bibliografía completa", pp. 208-209. 
dose físicamente y psicológicamente, hasta que asume su propia muerte cuando Yamam decide abandonarla. El suicidio es la materialización de una frase perdida en los cuadernillos que escribe: "me basto yo sola para amarlo”. El relato de Desideria Oliván, su gozo y su agonía han sido tratados fundamentalmente desde una perspectiva de género ${ }^{48}$.

Como también sucediera en el teatro, las protagonistas de las novelas de Gala desarrollan en su caracterización una importante relación analógica con los espacios. El jardín, espacio más representativo de su novelística, ha sido objeto de estudio por la crítica. En una entrevista realizada por Emilia Ruiz Martínez, el escritor revelaba que en todas sus novelas existe la invitación a salir del «jardín» propio. "Es una metáfora positiva - concluye-: lo negativo reside en nosotros mismos, que somos malos administradores al obrar como dueños de ese paraíso" ${ }^{49}$. El traspaso del jardín es necesario para hallar un espacio nuevo en el que se vea realizada la identidad del "yo". Así sucede no solo en La pasión turca, sino también en Mas allá del jardin (1995), Las afueras de Dios

48 En este contexto, véanse los siguientes estudios: Emilia Cortés Ibánez, "Desideria Oliván, protagonista de La pasión turca", en Actas del V Simposio Internacional de la Asociación Andaluza de Semiótica, eds. María I. Navas, Jose Valles y Jerónimo de las Heras, Almería, Universidad de Almería/Asociación Andaluza de Semiótica, 1995, pp. 127-138; Astrid A. Billat, “¿Con o sin la protagonista en Estambul?”, en La imposibilidad de "la mujer" en cinco novelas postfranquistas, Nueva York, Peter Lang, 2004, pp. 45-60; y Eunice Doman, "Antonio Gala's La pasión turca: Loving Too Much", Letras peninsulares, XVIII, 2-3 (2005), pp. 326-338. En otro orden, la novela se ha estudiado a la luz de convenciones del género erótico de la mano de Katarzyna Popek-Bernat ["The Conceptual Images of Erotic Relations in Spanish. Analysis of Some Linguistic Aspects of the Turkish Passion by Antonio Gala”, Cognitive Studies, XI (2011), pp. 321-336]. Por citar otra línea de investigación, desde el marco de los estudios culturales Nicola Gilmour ha tratado la presencia de la cultura islámica en la novela ["Turkish Delight: Antonio Gala’s La pasión turca as a Vision of Spain's Contested Islamic Heritage", Arizona Journal of Hispanic Cultural Studies, X (2006), pp. 77-94]. Por último, en el II Congreso Internacional "Antonio Gala: de la palabra al arte", Blas Sánchez Dueñas se ocupó de la recepción literaria y cinematográfica de la obra de Gala, con especial mención de La pasión turca y Más allá del jardín (ponencia inédita).

49 Emilia Ruiz Martínez, "En el jardín de Antonio Gala”. Espéculo. Revista de estudios literarios, XXI (2002), s.p.: https://webs.ucm.es/info/especulo/numero21/a_gala. html» [Consulta: 28/2/2018]. 
(1999), La regla de tres (1996) o Los papeles de agua (2008). Pero es sin duda en Más allá del jardín donde este espacio emerge como lugar simbólico por excelencia.

A propósito de esta novela, Ma del Amor Martín Fernández explora el jardín galiano a través de cuatro tópicos: el locus amoenus (espacio placentero), el hortus conclusus (espacio cerrado), el locus agrestis (espacio salvaje) y, por último, el jardin potager (espacio del renacimiento) ${ }^{50}$. A esta relación, que puede hacerse extensible a las novelas citadas, Clara Cobo añade un último espacio cultivado en su teatro: el jardín edénico ${ }^{51}$. Ese territorio del ideal — como lo concibe Martínez Moreno en 1994_, alcanzable e inasible a un tiempo, sirve de metáfora para explicar en las novelas la plenitud del sentimiento amoroso y también la expulsión del paraíso cuando el amor se diluya y viva, ya sin pretexto, en el recuerdo. Las travesías vitales de estas protagonistas — todas emprenden un viaje, todas pierden al ser amado, todas pierden un hijo- pueden ser entendidas como un vía crucis ${ }^{52}$, pero igualmente como un camino de reconocimiento que culmina con la comprensión del "yo" entendido reflexivamente:

Palmira [Más allá del jardín] es la única de los personajes protagonistas de Gala que no escribe, pero también la única que verá restaurada la pérdida del hijo. La descendencia del resto, Clara Ribalta [Las afueras de Dios] incluida, será literaria, fruto de esa "experiencia personal de mujer" que les conduce a la muerte, no sin antes haber escrito su propia historia que sus lectores ficticios, a modo de hijos póstumos, velarán por publicar ${ }^{53}$.

50 Ma del Amor Martín Fernández, "Literatura y transformación social: el simbolismo del jardín, invitados y excluidos", en Antonio Gala y el arte de la palabra, pp. 281298.

51 Clara Cobo Guijarro, "El abandono del jardín o la delimitación de un nuevo espacio narrativo en las novelas de Antonio Gala: El viaje al cuerpo", Ámbitos: Revista de Estudios de Ciencias Sociales y Humanidades, XXXVII (2017), pp. 71-82 (pp. 77-80).

52 Véase Eliana Machado Meugé, Le 'chemin de croix' de l'héroïne dans quatre romans d'Antonio Gala: "La pasión turca", "Más allá del jardin", "Las afueras de Dios" et "La regla de tres", Lille, Atelier National de Reproduction des Thèses, 2003.

53 Clara Cobo Guijarro, "El abandono del jardín o la delimitación de un nuevo espacio narrativo en las novelas de Antonio Gala: El viaje al cuerpo", p. 80. 
Salvo en Más allá del jardín, todos los personajes de las novelas de Gala muestran la necesidad de escribir. Esta asignación de personajes escritores y personajes lectores — narradores y narratarios — evidencia en la diégesis un proceso de producción textual característico de la novela fenomenológica. Los prólogos y advertencias de estos libros, generalmente utilizados para justificar la técnica del manuscrito encontrado, adquieren una función relevante y han sido analizados con detalle por Blas Sánchez Dueñas, con especial hincapié en El Manuscrito Carmesi ${ }^{54}$.

Precisamente, esta novela, con amplia acogida de crítica y público, ha contribuido al debate académico en torno al género de la novela históri$\mathrm{ca}^{55}$. Este relato sobre Boabdil o, mejor dicho, sobre el Boabdil que Gala ficcionaliza, entreteje los acontecimientos que giran en torno a la conquista de Granada junto con el descubrimiento del mundo interior de un hombre que nunca quiso ser Rey. La cuestión genérica se complica, máxime cuando esta novela y, más adelante, también El pedestal de las estatuas, publicada en 2007, son ofrecidas al lector en forma de autobiografías ficticias; una modalidad que, además, se integra en una estructura metaficcional. Lo que Gala logra, de nuevo, es la reconstrucción de la memoria, pero no solo de la memoria individual — como sucede con sus personajes

54 Blas Sánchez Dueñas, "Funciones y caracteres del prólogo en la narrativa de Antonio Gala”, en Antonio Gala y el arte de la palabra, ed. cit., pp. 299-316.

55 Sobre esta cuestión véanse especialmente los estudios de François Dubosquet: "Historia e historia de una vida: El manuscrito carmesí, de A. Gala", en Biografías literarias (1975-1997), coords. José N. Romera Castillo y Francisco Gutiérrez Carbajo, Madrid, Visor, 1998, pp. 387-399; "El manuscrito carmesi ou l'Histoire revisitée”, en Ecriture(s) et Histoire, Angers, Université d'Angers/ Centre de Recherche Inter-langues Angevin, 2001, pp. 289-304; "Entre Ecriture de l'Histoire et quête identitaire, El manuscrito carmesi d'Antonio Gala”, en La Fiction romanesque actuelle dans les pays de langues romanes et la problématique identitaire, ed. Rita Olivieri Godet, Rennes, PUR, 2010, pp. 223-242; y “¿Novela histórica o Historia novelesca?”, en Antonio Gala y el arte de la palabra, pp. 257-280. Pueden consultarse también Ma del Carmen Aldeguer Beltrá, "Técnicas de reconocimiento en una novela histórica de memorias: El manuscrito carmesí, de Antonio Gala”, en La novela histórica a finales del siglo XX: actas del V seminario Internacional del Instituto de Semiótica Literaria y Teatral de la UNED, coords. José Romera Castillo y Mario García-Page Sánchez, Madrid, Visor, 1996, pp. 119-126; y Friederike Heitsch, Antonio Gala y el Islam, Kassel, Reichenberger, 1995. En otra perspectiva, El manuscrito carmesi ha sido objeto de estudio en lo relativo a su traducción a otras lenguas. 
femeninos-; gracias al contexto histórico de estas obras, "la identidad pasa por la vía de la memoria colectiva" ${ }^{\prime \prime}$, tal y como apunta Dubosquet:

A partir de ficciones, pero que interrogan la versión histórica imperante hasta la fecha, Antonio Gala propone una creación que se sitúa entre investigación ontológica y construcción etobiográfica. Sin embargo, no olvidemos que estas novelas son ante todo una obra literaria: por la magia de las palabras, perfectamente domada, nace un relato en primera persona que da cuerpo y vida a unos capítulos de la Historia de España ${ }^{57}$.

Gala aborda estas historias novelescas — como él mismo las definióigual que en su día se aproximó a su teatro con referencias históricas (también denominación del autor). Su última intención, como también pudo comprobarse en la serie televisiva Paisaje con figuras, es la de bajar del pedestal a las estatuas.

El proceso de mitificación de los perdedores desconocidos y de desmitificación de los vencedores reconocidos ha sido, quizá, la principal constante en su escritura creativa. Esta tampoco pasa inadvertida para quienes estudian su novelística. Esta máxima alcanza a los personajes históricos ${ }^{58}$, pero también a las mujeres protagonistas de sus novelas ${ }^{59}$, quienes se verán obligadas a desmitificar a sus amados en su intento de saber reconocerse.

\section{Antonio Gala, poeta}

Lamentablemente, la poesía de Antonio Gala es el género más descuidado en el conjunto de los estudios académicos, a pesar de que fue su ejercicio literario más temprano. Décadas atrás, Díaz Castanón afirmaba que la obra de Gala orbita en torno a dos cuestiones fundamentales: "la necesi-

56 François Dubosquet, “¿Novela histórica o Historia novelesca?”, p. 278.

57 Ibidem, p. 278.

58 Benhamamouche Fatma, "Le mythe de Boabdil dans El manuscrito carmesí de Antonio Gala", en Héroes, mitos y monstruos en la literatura española contemporánea, coord. Fidel López Criado, Santiago de Compostela, Andavira, 2009, pp. 193-200.

59 Phyllis Zatlin, "Variantes de desmitificación en la obra de Antonio Gala", pp. 247252. 
dad de participar con la escritura en las luchas de su tiempo y la honda urgencia de realizar en ella su yo más íntimo" ${ }^{00}$. La primera de ellas ha sido tratada con exhaustividad en los estudios sobre teatro, y la segunda, que por razones lógicas queda ligada a la poesía, se ha explorado en menor medida. María José Porro Herrera se plantea la causa de la escasez de fuentes críticas sobre este género y aporta convincentes razones:

\begin{abstract}
[...] El desconocimiento de los recopiladores, puesto que Gala publicó muy poca poesía durante bastante tiempo, salvo esporádicamente en algunas revistas; más tarde también a causa de los inconvenientes que se derivan de la "publicitación selectiva de los intermediarios culturales" atraídos por otros autores u otros temas; también habría que pensar en que su labor poética se haya visto oscurecida por el éxito de su teatro; sin embargo, hay que tener presentes las abundantes declaraciones hechas por el autor en las que dice haber mantenido deliberadamente su producción poética más reservada y relegada a la intimidad, porque, frente a una misión social reconocida en el caso del teatro, en el de la poesía no está obligado a ello ${ }^{61}$.
\end{abstract}

En la actualidad, la práctica poética de Antonio Gala sigue siendo una tarea pendiente en el seno de los estudios literarios. No obstante, esta carencia no pasó inadvertida en el I Congreso Internacional "Antonio Gala y el arte de la palabra", celebrado en Córdoba en 2008. Dos ponencias se dedicaron entonces a la poesía cultivada por el autor. José Manuel Caballero Bonald trazó una panorámica sobre el conjunto de su corpus poético, y María José Porro Herrera elaboró para la ocasión un extenso y exhaustivo trabajo sobre el recorrido del autor en este género, examinado desde varios prismas. Recientemente, otros estudiosos se han asomado a su labor poética, así que a través del buen hacer de estos autores estableceremos de forma superficial los principales focos de interés, primeras huellas de un camino abierto a desarrollos futuros.

El "arte de la palabra" que atribuyen a Gala alcanza en la poesía su mejor concreción. "Al escribir, la caligrafía es icono y signo de la identidad del

60 Carmen Díaz Castañón, "Introducción”, en Antonio Gala, El águila bicéfala, ed. Carmen Díaz Castañón, Madrid, Espasa-Calpe, 1994, pp. 9-38 (p. 11).

61 María José Porro Herrera, “Antonio Gala: cauces poéticos", en Antonio Gala y el arte de la palabra, pp. 33-69 (p. 35). 
autor: Gala es aquello que escribe”, apunta Martínez Moreno, para después añadir: "La palabra de Gala, que es palabra de amor, lo es por emerger tránsida de lirismo"62. Su palabra poética es consecuencia de una actitud poética. No en vano, él ha concebido siempre su poesía como "poesía de poemas", dando a entender que el carácter poético rocía todo lo que escribe.

Gala comenzó a escribir poesía en plena adolescencia. Sus poemas se publicaron inicialmente en revistas literarias de la época. Sin embargo, muchos de aquellos no se incluirían en poemarios hasta mucho tiempo después. La unificación del corpus es, por tanto, en sí misma un objeto de estudio ${ }^{63}$. En 1959 recibe el accésit del Premio Adonáis por Enemigo intimo, editado en 1960. Empero, la publicación de sus poemas sueltos y poemarios no se efectúa de forma cronológica, tal y como asevera José Infante:

Así encontraremos dos entregas de libros, aparecidas ambas en 1962 y 1965 respectivamente en Cuadernos Hispanoamericanos. Me refiero a La deshora y a Meditación en Queronea. Estos dos textos son, sin duda, inmediatamente posteriores a Enemigo intimo y como este participan de las mismas características estilísticas. Sin embargo, hay un libro anterior a Enemigo intimo y se llama Perseo. Y al menos otros tres: La acacia, Valverde, 20 y Baladas y canciones, que hay que situar por la forma y el estilo antes que La deshora y Meditación en Queronea. No es hasta 1997, con ocasión de la publicación de la antología Poemas de amor, publicada por Planeta y prologada por el poeta y académico Pere Gimferrer, cuando el propio Gala da a luz una selección hecha por él mismo de todos estos libros, anteriores a Enemigo intimo, como Perseo y los que se fechan entre el libro distinguido en Adonáis y las entradas publicadas en Cuadernos hispanoamericanos, de La deshora y Meditación en Queronea ${ }^{64}$.

62 Isabel Martínez Moreno, "Memoria y profecía", en Antonio Gala: eterno y de Cristal, pp. 11-105 (p. 67).

63 Esta cuestión se aborda como apartado en el trabajo de Porro Herrera ya referido: "Las revistas literarias"). En este contexto también son relevantes las siguientes publicaciones: José Infante, Antonio Gala: Un hombre aparte, Madrid, Espasa-Calpe, 1994; Fanny Rubio, Las revistas poéticas españolas (1939-1975), Alicante, Universidad de Alicante, 2004; y la tesis doctoral inédita de Rafaela Valenzuela, titulada Revistas literarias de posguerra en Andalucía (1949-1959), Córdoba, Universidad de Córdoba, 1986.

64 José Infante, "El alma andaluza de Antonio Gala a través de su poesía”, en Antonio Gala: Eterno y de Cristal, pp. 159-168 (p. 162). 
El de 1997 es un año especialmente importante, pues la edición de Poemas de amor no supone solo la publicación de textos inéditos hasta la fecha, sino la colaboración del propio poeta en su selección: "Estas líneas son una confidencia. Como el resto del libro: la confidencia de un poeta desconocido que con ella se presenta. A pecho descubierto" (1998, p. 9). Además de los poemarios citados, este libro incluye otros títulos: Para Mirta (Sonetos barrocos) (¿?); Los sonetos de la Zubia (1966-1987); Testamento andaluz (1985) y Tobias desangelado65. Este último no lo había dado por concluido entonces. En 2005 vio la luz El poema de Tobias desangelado ${ }^{66}$.

A propósito de las constantes de su modalidad lírica, Porro Herrera sintetiza — de la mano de las declaraciones de Gala- que el amor es el común denominador de su expresión poética desde su primera obra adolescente, Perseo (1947? $)^{67}$. En este punto se menciona una línea de investigación sobre la que ya se habían arrojado algunas aportaciones. Díaz Castañón (1993) contribuyó brevemente a la explicación de esta vertiente tematológica en una edición de sus principales textos de amor: "Si en Enemigo intimo (1960) el amor se conceptualiza como la imposible proyección exacta [de uno mismo] en el otro, [...] en los veintisiete sonetos de la Zubia (1987) [...] el amor es ya plenamente un armónico conjunto de desarmonías" ${ }^{68}$. Sobre Enemigo intimo, Caballero Bonald añadió después: "El amor no es ya solo una experiencia desesperada, apasionadamente vivi-

65 Los sonetos de la Zubia contiene Once sonetos de la Zubia (Jarazmín, 1981) junto los que aparecieron en $A B C$ literario el 7 de noviembre de 1987 bajo el nombre de «Veintisiete sonetos de la Zubia».

66 Otros libros son: Meditación en Queronea. Poema VIII (Dardo, 1987); Poemas cordobeses (Ayuntamiento de Córdoba, 1994); Baladas y canciones. Sus mejores poemas de amor (Planeta, 1999); y, publicado en el último año, Sonetos y otros poemas (Eirene, 2018). Véase la relación completa de sus poemarios en Clara Cobo Guijarro, "Antonio Gala: bibliografía completa”, p. 206.

67 También Caballero Bonald arropa esta idea: "Lo que sí resulta llamativo es que, si se tiene en cuenta el conjunto de los poemas escritos por Antonio Gala, la casi totalidad de ellos son de tema amatorio, con lo que también podría decirse que esta edición de la que estoy hablando de Poemas de amor se acerca mucho en sus justos términos a unas poesías completas" [José Manuel Caballero Bonald, "La expresión poética de Antonio Gala", en Antonio Gala y el arte de la palabra, pp. 25-33 (p. 26)].

68 Carmen Díaz Castañón, "Introducción”, en Antonio Gala, El águila bicéfala, p. 20. 
da junto a los registros de la belleza, sino un método de salvación personal, una forma de escapada del entorno inhóspito y amenazador" ${ }^{69}$. En relación con esta idea, Porro Herrera considera conveniente vincular el sentimiento amoroso con la noción de paraíso perdido: "Es aquí donde creemos que pueden tener aplicación las tesis de Isabel Martínez aplicadas a la poesía: el autor se siente exiliado de un Edén: busca un paraíso perdido que intenta recuperar a través del amor [...]"70. Pero el amor presenta diversas caras en esta persistente búsqueda. A juicio de Porro Herrera, si La acacia está impregnado de un sentimiento de pérdida, en Valverde 20, el amor se desposee de un espacio antropomórfico: "es al amor en sí a quien se espera"71. La ausencia se hace de nuevo palpable en Baladas y canciones y en La deshora. En este último, de acuerdo con Infante: “[...] hay una acentuación del sentido metafísico y trascendente en el tratamiento de los temas, en los que sigue dominando una mirada melancólica sobre el paso del tiempo y la fugacidad del amor"72. Meditación en Queronea es para Porro Herrera un "libro simbólico, acaso el más intensamente protagonizado por el Amor en su entrega total hasta llegar al sacrificio cruento: el mundo es el campo de batalla donde gloriosa y finalmente sucumbe el amor, pero de donde paradójicamente resurgirá glorioso para ejemplo de amantes"73. Pero es en Sonetos de la Zubia donde se recrea indudablemente el lugar edénico:

\begin{abstract}
Alberga este espacio toda suerte de experiencias, estados y situaciones de amor (que no amorosas), en las que el Amor (con mayúsculas) se erige en protagonista y conjura al yo poético a expresarse en los extremos que se mueven entre "el fervor y la gelidez, el piropo y el ultraje, la convivencia feliz y la soledad". En sentido etimológico "zubia" es una voz procedente del árabe y significa "lugar por donde corre o donde afluye, mucha agua". En nuestro poeta, además, es un locus amoenus granadino, localizable en un mapa: es sin duda un "lugar edénico" del que se ha sido expulsado y un "lugar paradisíaco" al que se aspira poseer $[\ldots]^{74}$.
\end{abstract}

69 José Manuel Caballero Bonald, op. cit., p. 27.

70 María José Porro Herrera, op. cit., p. 45.

71 Ibidem, p. 52.

72 José Infante, "El alma andaluza de Antonio Gala a través de su poesía”, p. 165.

73 María José Porro Herrera, op. cit., p. 57.

74 Ibidem, p. 59. 
El protagonismo de este espacio geográfico determinado, en plena naturaleza granadina, y su correspondiente dimensión simbólica son extrapolables a otros lugares evocados en sus poemarios.

La configuración de los espacios escénico y narrativo — su funcionalidad psicológica, sociológica, alegórica...- se ha sondeado en profundidad, tal y como se ha comprobado en anteriores páginas. Sin embargo, en la poesía de Gala esta cuestión ha sido abordada superficialmente, pero en la medida justa para propulsar un foco de estudio con muchas posibilidades. El poema de Tobias desangelado, publicado en 2005, es para Caballero Bonald, "un cuaderno de ruta" en el que el viajero-peregrino vuelca sus experiencias $^{75}$. A través de su lectura los receptores se suman a un viaje enamorado - en palabras de Gala-, con más de cien escalas que trazan un mapa biográfico. En esta obra el espacio alberga una función referencial-descriptiva de los lugares aludidos; una función psicológica-expresiva del "yo" poético, y una función simbólica-alegórica de los diversos "paisajes amorosos". Esta última función ya latía en Testamento Andaluz (1985). Este poemario, acompañado de dibujos a color de Manolo Rivera y de composiciones musicales de Manolo Sanlúcar, supuso un hermoso homenaje a Andalucía. Los topónimos que dan título a las creaciones aquí incluidas — veinticuatro poemas en verso libre— concretan la dimensión simbólica de estas creaciones: "se convierten en referente emocional no necesariamente erótico y sí cercano a un misticismo panteísta en que se funden Amor, Belleza y Eternidad"76.

También han suscitado interés las referencias literarias que inspiran, nutren e incluso se citan expresamente en la poesía de Gala. En los ańos noventa Romera Castillo ya analizó los paralelismos de actitudes con san

75 José Manuel Caballero Bonald, op. cit., p. 31.

76 María José Porro Herrera, op. cit., p. 28. Son muchos los ejemplos planteados por la autora: "[...] una circunstancia como el recuerdo, la belleza —-Sierra de Córdoba'-, panteísmo amoroso — 'Playa de El Palo'—, nominalismo transgresor — 'Alhambra'-, un deseo, carpe diem — 'Arcos de la Frontera'-, eternización del instante — 'Sevilla'-, la ensoñación —'Níjar'-, evocación de lugares míticos de ensueño —-Albaycín'-, de reposo eterno - 'Cartuja de Jerez' - o el símbolo de la entrega absoluta por amor, como 'Guadalquivir en Sanlúcar”' (María José Porro Herrera, ibidem, p. 63). 
Juan de la Cruz ${ }^{77}$, y en los estudios aludidos también se ha contribuido al desarrollo de esta cuestión ${ }^{78}$. Caballero Bonald insiste en el "barroquismo sustancial” del poeta, siempre vinculado a la tradición poética arábigoandaluza $y$, especialmente, a la lírica barroca, que, junto con referentes del siglo XX, entona su voz poética: "Góngora, Villamediana, Lope, Bocángel, Soto de Rojas, Carrillo de Sotomayor etc., pasa por Cernuda y Aleixandre y culmina en el modelo suntuoso de los poetas de Cántico, encabezados, como bien se sabe, por Pablo García Baena y Ricardo Molina"79. Porro Herrera se ocupa de esto en su apartado "Estudio crítico: Antonio Gala y las corrientes poéticas de su tiempo" e incluso amplía el abanico de Caballero Bonald:

\begin{abstract}
Antonio Gala se alinea no ya con otros escritores contemporáneos, sino especialmente con toda una cadena cultural que le hace contar entre sus maestros predecesores y guías con ciertos nombres del 27: García Lorca, Aleixandre, Salinas y sobre todo Cernuda, a figuras imprescindibles como Rubén Darío, Juan Ramón Jiménez, Antonio Machado y los poetas modernistas y simbolistas —Rilke- [...]. Podemos remontarnos cronológicamente mucho más atrás en las fuentes literarias hasta llegar a Góngora, la poesía arábigo-andaluza y el mundo clásico, sobre todo Santa Teresa y San Juan de la Cruz, cuyos versos incrusta con frecuencia entre los suyos ${ }^{80}$.
\end{abstract}

Gala, ya lo hemos dicho, es hombre de fidelidades, y estas referencias le acompañan, de forma casi obsesiva, en su trayectoria literaria no exclusivamente poética. Este ejercicio de consumada intertextualidad puede

77 José Romera Castillo, Con Antonio Gala (estudios sobre su obra), pp. 273-280.

78 Esta línea de investigación puede considerarse activa, máxime si tenemos en cuenta que en el III Congreso Internacional «El arte de la comunicación» (Córdoba, 15-16 de noviembre de 2018), Andrés Amorós, en su ponencia "Un cancionero andaluz: los sonetos de la Zubia”, dedicó buena parte de su intervención a la intertextualidad presente en esta obra. Asimismo, otra propuesta de análisis quedó expuesta en la ponencia de Porro Herrera titulada "Interrelaciones culturales en la poesía de Antonio Gala" (II Congreso Internacional «Antonio Gala: de la palabra al arte», Córdoba, 11-13 de marzo de 2015).

79 José Manuel Caballero Bonald, op. cit., p. 30.

80 María José Porro Herrera, op. cit., p. 44. 
entenderse como otra de las razones de su demandada independencia respecto a la inclusión de su poesía en una corriente determinada ${ }^{81}$.

El poeta, en suma, tiene una misma concepción del amor y la poesía, pues ambos se comprenden como un hermoso e interminable proceso de conocimiento $^{82}$. Hasta aquí se han expresado muy someramente algunos objetos de estudio que, sobre su "poesía de poemas", se han abordado en los últimos años. Esperemos que, en los venideros, la cosmovisión poética de Antonio Gala sea objeto de nuevas reflexiones.

\section{Antonio Gala, articulista y guionista}

La producción de Antonio Gala no se ajusta en exclusividad a los géneros literarios, pues las constantes de su discurso han llegado a sus lectores a través de artículos y crónicas publicadas en los principales diarios desde los años setenta hasta que firmó su última "tronera" para el diario El Mundo el 21 de diciembre de 2015. Como articulista, Gala adoptó múltiples perspectivas, desde el periodismo de opinión tan característico de "La proa" y "La tronera", hasta otro tipo de crónicas, más intimistas, abordadas generalmente desde la segunda persona. De acuerdo con Dubosquet, "sus crónicas se volvieron un verdadero encuentro, un espacio de debate, y suscitaron reacciones y reflexiones tal y como lo ilustran el numeroso correo de lectores.

81 Ibidem, p. 41-44. La inclusión en la Generación del 50 corresponde a Gala por su fecha de nacimiento y por las fechas de sus publicaciones. Según Porro Herrera, "Antonio Gala cuando habla de su teatro se manifiesta sobre su pertenencia o no a un 'grupo generacional' afirmando su 'independencia en todo, no solo en la obra, sino en la vida', nada más lejos pues de reconocerse 'dentro de nada' y lo que afirma para el teatro bien podemos aplicarlo a su poesía” (Ibidem, p. 43). José Infante incide en la proximidad de Antonio Gala con dicha generación en muchos de sus postulados, aunque asimismo se separe de ella por una "voluntad de estilo" y una "acusada voluntad de clasicismo" (José Infante, "El alma andaluza de Antonio Gala a través de su poesía", p. 168).

82 "Para nuestro autor - asevera Porro Herrera- la poesía consiste en 'algo que no es más que una vía de conocimiento' (Poemas de amor, p. XIII), que parte de un yo y que como una flecha se dirige inexorablemente al otro, en cuya reacción de rechazo o aceptación el yo poético no solo recibe placer o dolor, sino que experimenta algo más profundo consistente en la percepción especular de su propia otredad, en definitiva, de su autoconocimiento" (María José Porro Herrera, op. cit., p. 42). 
La presencia del autor en las principales cabeceras nacionales es la prueba de la importancia de su escritura y de la caución moral que significa" ${ }^{\prime 3}$. Antonio Gala escribió en Pueblo (1970), Sábado Gráfico (1973-1978), Repórter (1977), Primera Plana (1977-1978), La Actualidad Española (1978), El País (1978-1995), El Mundo (1991-2015) o El independiente (1988-1990).

Los artículos y columnas del escritor cordobés han sido recopilados en múltiples libros, como, por ejemplo, Charlas con Troylo (1981), En propia mano (1983), Cuaderno de la dama de otoño (1985) o Dedicado a Tobias $(1988)^{84}$. Los prólogos que se incluyen en estas ediciones ofrecen las primeras reflexiones sobre la incursión de Antonio Gala en los medios de comunicación. Estos, firmados por Andrés Amorós, Juan Cueto o José María Gala, se suman a las investigaciones que se han desarrollado hasta la actualidad.

A propósito del ejercicio periodístico de Gala, Dubosquet ha analizado desde 1989 temas tan variados como la relación entre literatura y prensa; el uso del lenguaje y las expresiones populares en sus textos; la historia española reciente a través de la mirada de Gala, y, especialmente, el concepto de "intelectual" en el ámbito de los medios de comunicación ${ }^{85}$. La erudición y el compromiso son los rasgos que definen la práctica periodística del cordobés:

83 François Dubosquet, "Las tres fidelidades de Antonio Gala", ed. cit., p. 185.

84 Véase la lista completa: Clara Cobo Guijarro, "Antonio Gala: bibliografía completa”, p. 209.

85 Véanse los siguientes trabajos de François Dubosquet: "La columna entre literatura y periodismo, de la hoja caduca al ramo perenne", en La morfología de la prensa y del impreso: la función expresiva de las formas. Homenaje al profesor Jean Michel Desvois, París, PILAR, 2010, pp. 261-277; "Paremia y prensa. Presencia y función de los proverbios, refranes y expresiones populares en la obra periodística de Antonio Gala", Paremia, VI (1997), pp. 195-201; "La invitación al viaje", Revista internacional DIGILEC, XI, 1 (2014), pp. 124-138. «http://revistas.udc.es/index.php/DIGILEC/ article/view/digilec.2014.1.0.3664» [Consulta 2/2/2019]; "Intelectual y prensa", en Historia y sociedad comparada y otros estudios (Vol. VI), eds. Florencio Sevilla y Carlos Alvar, Madrid, Castalia, 2000, pp. 318-328; "Las tres fidelidades de Antonio Gala”, pp. 181-187; y "Antonio Gala: un écrivain citoyen”, en Intelectuales y medios de comunicación en los espacios hispanófono y lusófono (siglos XIX-XXI). Homenaje a Marie-Claude Chaput, eds. François Dubosquet, Nadia Ait Bachir, Nathalie Ludec y Aranzazu Sarría Buil, Caen, PILAR, 2017, pp. 189-210. 
Antonio Gala es, ante todo, un Intelectual, un Humanista de sólida formación universitaria, con esa capacidad extraordinaria de expresar el pensamiento de una comunidad, de aconsejar, de superar lo individual, para expresar lo universal. Ser intelectual no le confiere inmunidad sino todavía más responsabilidad que derechos, o por lo menos tanta responsabilidad como la libertad de expresión que este estatuto le confiere. Ser intelectual es para él, ante todo, un acto de humildad, un compromiso cívico ${ }^{86}$.

En esta línea, Juan Cueto relaciona el enfoque culto de Gala —inequívocamente plasmado en sus textos periodísticos - con la íntima conexión que desarrolla con una multitud de receptores heterogéneos: "Tampoco escribe Antonio Gala para una sola edad, una sola cultura, un solo sexo, una sola clase social, una sola sensibilidad [...]. Para decirlo de manera precisa: Antonio Gala escribe para la muchedumbre solitaria" ${ }^{87}$. El éxito de las crónicas de este escritor "solitario solidario" 88 sin duda se debió al tratamiento de los grandes temas universales de su literatura - amor, amistad, muerte, libertad, esperanza...- - pero focalizados desde la realidad del momento presente en el que esa muchedumbre, también solitaria, trató de entender y convivir en la España contemporánea:

La poesía, los relatos, los artículos, el teatro, las sinopsis o la novela no tienen otra meta que participar en esta reflexión de cada ser humano frente a su destino. Así si su poesía habla del amor y desamor, de sus muertes o traiciones, los relatos evocarán la amistad y la separación de seres; los artículos, las angustias de una sociedad en busca de nuevas referencias en este final de siglo, frente a problemas tan diversos que van del terrorismo, pasando por la insumisión o la objeción de conciencia, a una nueva ética — reflexión sobre el divorcio, el aborto, las drogas: tres asuntos, temas de debate legislativo-, del papel de la Iglesia y del Ejército, del civismo, del paro, del culto a los muertos, los mercados; el teatro nos hablará de los

86 François Dubosquet, "Las tres fidelidades de Antonio Gala", pp. 181-182.

87 Juan Cueto, "Prólogo", en Antonio Gala, En propia mano, Madrid, Espasa-Calpe. 1983, pp. 11-23 (p. 18).

88 François Dubosquet Lairys, “Antonio Gala, un regard sur l'Espagne des anées 80", Hispanistica XX, VII (1989), pp. 71-76 (p. 73). 
vencidos, de tolerancia, de libertad, o de las dudas del poder, nos llevará hasta los mitos de la Ilíada para reflexionar sobre el hombre maduro, evocará el sacrificio de Jimena entre amor y razón de Estado, la OTAN y las autonomías, la soledad y la homosexualidad, las cárceles donde se encierra el hombre, nos confiará su fe y duda en el hombre: "El ser humano es torpe, deslumbrante, competidor, suicida, menesteroso, inagotable, ruin, magnífico, egoísta, insustituible. El ser humano es a la vez Caín y Abel. Eso es lo único con lo que contamos. Estamos hechos con la humilde y gloriosa madera de los sueños. Con la madera se puede construir un laúd o un patíbulo" (Gala, 1/2/81). La novela será otra forma de acercarse a los mismos problemas: El manuscrito carmesí nos llevará al encuentro de un vencido y presentará una maravillosa reflexión sobre la identidad andaluza; La regla de tres nos conducirá a una íntima reflexión sobre el ser humano frente a la muerte, a su otoño y este sentimiento tan tremendamente humano que invade toda su obra: el amor. En fin, cada poema, cada texto se volverá una entrañable reflexión sobre la condición humana, una condición fuertemente enraizada en lo cotidiano de cada español. Gala se presenta fundamentalmente como un humanista ${ }^{89}$.

Sin abandonar nunca su condición de intelectual, pero desde su posición de conciudadano, Gala encuentra en su particular uso de la palabra la mejor conexión con su público. Su discurso se tiñe de humor, ironía y juego, pero combinado con hondas reflexiones y el uso de un extenso acervo con el que celebra constantemente nuestra lengua. Asimismo, el empleo de refranes y expresiones populares fluyen en un discurso culto sumamente cuidado.

Hemos de tener en cuenta que Gala ha colaborado en la prensa escrita durante cincuenta años. Si bien se han estudiado las facetas principales de esta especial relación entre literatura y periodismo que encarna el autor, quedan aún varios vacíos por colmar, como, por ejemplo, la presencia de la mujer en estas crónicas. Se antoja un sugerente prisma, no solo porque el universo femenino ha sido estudiado con esmero en su teatro y sus novelas, sino principalmente por la revolución social que han protagonizado las mujeres en la sociedad de las últimas décadas.

89 François Dubosquet, "Antonio Gala, el concepto de fidelidad en un intelectual", Signa. Revista de la Asociación Española de Semiótica, VI (1997), pp. 161-186 (p. 168). 
Por último, no podemos dejar de referirnos a los guiones que escribió para Televisión Española, que, afortunadamente, han sido publicados en su totalidad ${ }^{90}$. Algunos de estos fueron $Y$ al final, esperanza (1967), Las tentaciones (1970), Si las piedras hablaran (1972), Cinco conmemoraciones [Eterno Tuy (1968), Oratorio de Fuenterrabia (1968), Auto del Santo Reino (1969), Retablo de Santa Teresa (1970) y El cantar del Santiago Paratodos (1971)] o Paisaje con figuras (1976 y 1984) ${ }^{91}$. Esta serie televisiva ha sido la que ha concentrado mayor atención de la crítica.

Exhibida en dos temporadas, 1976 y 1984, en Paisaje con figuras se narraba la vivencia de treinta y nueve personajes españoles que, en palabras de Romera Castillo (quien recoge declaraciones del propio Gala), no eran de "gran relumbrón (reyes, caudillos héroes o heroínas) sino 'personajes olvidados a veces; o peor, mal recordados, deformadas intencionadamente su vida e intenciones'. Las figuras elegidas — prosigue - 'tienen en común el que amaron a la patria, a la vida y a la libertad. La libertad y la vida como único instrumento de trabajar la patria" 92 . Se han ocupado de estos protagonistas Romera Castillo, Dubosquet, Antonio Cruz Casado o Martínez Moreno $^{93}$. La caracterización y no menor ficcionalización de estas figuras en su paisaje se suman al tratamiento de Gala de la historia de España

90 Véase el listado completo en Clara Cobo Guijarro, "Antonio Gala: bibliografía completa”, pp. 210-211.

91 Título que adquirió la recopilación de estos guiones televisivos publicados en su totalidad por Planeta-De Agostini en 1999. Anteriormente, la editorial Adra reunió en 1976 los cuatro primeros bajo el título de Cuatro conmemoraciones.

92 José Romera Castillo, "Rosalía de Castro (una figura en su paisaje) de Antonio Gala", Actas do Congreso Internacional de Estudios sobre Rosalía de Castro e o seu tempo, Santiago de Compostela, Consello da Cultura Galega/Universidade de Santiago de Compostela, 1986b, pp. 317-325 (p. 318).

93 José Romera Castillo, "Rosalía de Castro (una figura en su paisaje) de Antonio Gala", op. cit., pp. 317-325; François Dubosquet, "Voix de femmes galiciennes dans le paysage d'Antonio Gala", Galice-Bretagne-Amérique Latine: Hommage à Bernard Le Gonidec, Rennes, Cahiers du LIRA, 2000, pp. 131-141; Antonio Cruz Casado, "Bandolero andaluz en su paisaje: José María El Tempranillo, un guión de Antonio Gala", Antonio Gala y el arte de la palabra, pp. 347-360; e Isabel Martínez Moreno, "Apuntes para un boceto de El Greco, figura de Gala, a la luz de Manuel B. Cossío y Gregorio Marañón”, Tejedora de palabras. La lengua y la literatura en relación con los medios de comunicación, ed. Antonio Ubach, Madrid, Fragua, 2013, pp. 227-241. 
que ya había realizado en Si las piedras hablaran o en las Cinco conmemoraciones; y, a su vez, en su "teatro con referencias históricas” y, más tarde, en sus "historias novelescas". Gala no solo elaboró guiones originales para cine y televisión, sino que también adaptó para el formato televisivo obras de Shakespeare, Molière o Eurípides. Su faceta como guionista ha de ser estudiada en su conjunto, pues este patrimonio extraordinariamente valioso que Antonio Gala ha legado forma parte de la historia de la ficción televisiva en nuestro país.

\section{Conclusión}

Aunque quedan muchas claves dignas de ser evaluadas, especialmente en lo que respecta a los poemarios y a los libros de relatos, la obra literaria de Antonio Gala ha sido ampliamente explorada por la comunidad académica. Sin embargo, no siempre fue así. Por ello, no podemos dejar de hacer referencia a varios acontecimientos determinantes: el Curso de Verano de la Universidad Complutense de Madrid (1992), en el que por primera vez se reunieron los principales estudiosos de su obra; y, en segundo lugar, los tres Congresos Internacionales sobre Antonio Gala organizados por la Universidad de Córdoba y celebrados en 2008, 2015 y 2018 en la Fundación Antonio Gala para Jóvenes Creadores.

A lo largo de estas páginas se ha tratado de establecer una panorámica sobre la actividad investigadora de la crítica en torno a la obra del autor cordobés en el último medio siglo. Así, se han identificado las primeras aportaciones, los encuentros científicos, los autores principales, las líneas de investigación elegidas por estos y los aspectos que no se han tratado y que pueden ser desarrollados en lo sucesivo.

En estas líneas se ha podido comprobar que el teatro es, sin duda, el género más examinado y el que ha alcanzado mayor reconocimiento. Los estudiosos han valorado positivamente el talento de Gala a través de los elementos más llamativos de su dramaturgia: la cuidadosa elección de los recursos retóricos en sus piezas teatrales; la presencia de un componente intertextual magníficamente engranado en muchas de estas; la capacidad de visitar el pasado y desmitificar la historia sin dejar de reflejar, en el mismo ejercicio expresivo, el momento presente; la creación de espacios 
de opresión y redención para unos personajes siempre en búsqueda de sí mismos, y el tratamiento de los grandes temas humanos de la mano de sus protagonistas.

Gala siempre apostó por su independencia respecto a las corrientes literarias de su tiempo, especialmente con su poesía. Este género ha permanecido encubierto también para los círculos de investigación, pero no olvidemos que el autor quiso durante mucho tiempo que esta permaneciera bajo su abrigo, en la intimidad. No obstante, tal y como hemos indicado, el valioso trabajo de Porro Herrera sienta las bases y subraya los principales focos de interés de la práctica poética de Gala, que podrán desarrollarse pormenorizadamente en adelante.

Las novelas del autor cordobés han sido estudiadas dentro y fuera de nuestras fronteras hasta la actualidad, siendo las más celebradas El manuscrito carmesí y La pasión turca. Si la primera — junto a El pedestal de las estatuas - ha suscitado un debate en torno a su clasificación como novela histórica y su conceptualización como autobiografía ficticia, la historia de Desideria Oliván ha generado aportaciones en el ámbito de los estudios de género. También se ha podido observar que el autor ha mantenido muchas de las constantes de su teatro en su narrativa.

Por último, ha resultado de sumo interés la valoración de la participación de Gala en los medios de comunicación de nuestro país, pues el carácter intelectual de su discurso y el uso de un lenguaje poético nunca le han impedido conectar con un público de masas. Su sentido del humor, su franqueza y su manifiesta sensibilidad en el tratamiento de la información y de la ficción han propiciado que los espectadores de prime time y los millones de lectores de los principales diarios hayan recibido a Gala como a un conciudadano.

A lo largo de estas páginas hemos conocido la herencia literaria de Gala, pero lo mejor de sí mismo, como él mismo ha reconocido en múltiples intervenciones, se lo ha dejado a Córdoba: su Fundación. En ella, año tras año, jóvenes artistas de todo el mundo desarrollan su talento, enriquecido por la "fecundación cruzada". Este concepto, ideado por el propio autor, supone un aprendizaje transversal en el que las artes allí desarrolladas se retroalimentan, de tal forma que el músico aprenda del escritor y este del artista plástico. "Para mí — confiesa Gala — el arte y el amor siempre han tenido una cosa en común: su capacidad de dar a los 
seres humanos la conciencia de una grandeza que tienen en su interior pero que ignoran"94. La inauguración de su Fundación fue la culminación de un acto de amor, el coronamiento de su particular concepción de la creación artística. Recordemos: "el arte es una mesa común sobre la que pueden disponerse objetos muy diversos, más o menos costosos, más o menos bellos, pero sin la cual todo sería añicos"95. Gala —para quien la escritura siempre fue un destino- ha encontrado su verdadera vocación en la promoción de jóvenes venidos de todo el mundo para que desarrollen su talento con libertad en un extraordinario escenario. El hecho interartístico derivado de este proyecto será objeto de nuevas líneas de investigación en el futuro. Esta es razón suficiente para concluir que el legado de Antonio Gala es una fuente inagotable de riqueza.

Soy gubia, pincel, palabra, nota entre vosotros. Os recibi en nuestra casa y en ella, esperándoos, os dejé mi herencia. Aprovechad lo que os venga bien. Y guardad mi nombre bajo el vuestro como un intimo secreto de nuestros corazones. Gracias por venir. No os vayáis nunca. La Fundación es vuestra.

Antonio Gala

94 Antonio Gala, op. cit., p. 288.

95 Ibidem, p. 229. 